\title{
Poverty and government transfers in the United States
}

\section{Dierk Herzer \& Rainer Klump}

To cite this article: Dierk Herzer \& Rainer Klump (2010) Poverty and government transfers in the United States, Applied Economics Letters, 17:16, 1565-1569, DOI: $10.1080 / 13504850903051516$

To link to this article: http://dx.doi.org/10.1080/13504850903051516

册 Published online: 04 Jan 2010.

Submit your article to this journal $₫$

Џ Article views: 53

Q View related articles $\widetilde{ }$ 


\title{
Poverty and government transfers in the United States
}

\author{
Dierk Herzer* and Rainer Klump \\ Department of Economics, Johann Wolfgang Goethe-University, \\ Grüneburgplatz 1, 60323 Frankfurt am Main, Germany
}

This article examines the long-term impact of government transfers on poverty in the United States using cointegration techniques. In contrast to most existing studies, we find that government transfers play an important poverty-reducing role.

\section{Introduction}

The question of whether and how public transfer payments affect poverty in the United States has been debated for decades, with no consensus in sight. At the centre of this debate are basically two arguments. The first, intuitively obvious argument, which is based on the typically poverty-reducing role of public transfers, is that transfers decrease poverty by raising the incomes of the poor. According to the second argument, antipoverty benefits increase poverty by decreasing the labour supply of current and all potential future transfer recipients. The logic behind this is that antipoverty benefits act as a substitute for income from employment: increases in benefit payments thus make dependency on the government more attractive than the alternative of self-support. Furthermore, as the marginal poor become more dependent upon transfers and therefore spend less time working, their skills depreciate, in turn reducing their chances of finding a job, earning money and escaping poverty. Hence, because of the negative impact of higher transfer payments on work incentives, such payments can substantially raise the poverty rate - not only by increasing the number of transfer recipients but also by increasing the duration of poverty (e.g. Gwartney and McCaleb, 1985).

In fact, most empirical studies find neither any poverty-reducing effect of government transfers (e.g. Gottschalk and Danziger, 1984; Nieswiadomy et al., 1991; Balke and Slottje, 1993; Haveman and Schwabich, 2000; Formby and Kim, 2001; Vedder and Gallaway, 2001; Enders and Hoover, 2003; Hoover et al., 2004) nor even a statistically significant positive relationship between transfer payments and the poverty rate in the United States (e.g. Blank and Blinder, 1986; Peterson and Rom, 1989; Gundersen and Ziliak, 2004). To our knowledge, only the results by Osberg (2000) and Hoynes et al. (2005) suggest that government transfers lead to a statistically significant reduction in the poverty rate.

However, a limitation to these poverty studies is that they do not examine whether government transfers and poverty are cointegrated and thus whether there exists a long-term relationship between government transfers and poverty. Specifically, the approach in most of the prior studies is to use aggregate timeseries or long-term panel data (for the United States) to estimate the relationship between benefit payments and the poverty rate in growth rates or first differences (e.g. Balke and Slottje, 1993; Formby and Kim, 2001; Vedder and Gallaway, 2001; Enders and Hoover, 2003; Hoover et al., 2004). It is well known that the use of stationary first differences (or growth rates) avoids spurious correlations, but this approach precludes the possibility of a long-run or cointegrating relationship between the level of government transfers and the level of poverty a priori. Apart from that, recent advances in time-series and panel econometrics suggest that simply using first differences can lead to serious misspecification biases if a long-run or cointegrating relationship between the levels of the variables exists. Indeed, there are also some studies that estimate standard regression models of the relationship

*Corresponding author. E-mail: dierkherzer@wiwi.uni-frankfurt.de 
between the level of government transfers and the poverty rate (e.g. Gottschalk and Danziger, 1984; Blank and Blinder, 1986; Nieswiadomy et al., 1991; Haveman and Schwabisch, 2000; Gundersen and Ziliak, 2004; Hoynes et al., 2005). However, such regression models are subject to spurious correlation if government transfers and poverty rates are nonstationary and not cointegrated. But even in the presence of cointegration, standard regression models may produce biased results and, furthermore, the estimates are not normally distributed, implying that the reported significance levels may be misleading.

Thus, the objective of this article is to examine the long-run impact of government transfers on US poverty using cointegration techniques. To preview our main result: We find that, although government transfers have no statistically significant effects on the poverty rate in the short run, they significantly reduce poverty in the long run.

The rest of this article is organized as follows. Section II describes the estimating equation and the data. The empirical analysis is presented in Section III and Section IV concludes.

\section{Model and Data}

To investigate the long-term impact of government transfers on poverty in the United States, we use aggregate annual time-series data. Following previous studies (e.g. Enders and Hoover, 2003; Hoover et al., 2004), we employ the official US Census Bureau poverty rate as our measure of poverty, whereas our measure of government transfers represents all government transfers to low-income families including medical benefits and other noncash transfers such as food stamps and public housing. The government transfer data are from the Historical Tables of the Budget of the US Government, Fiscal Year 2006, and have been converted into real 2000 dollars using the implicit Gross Domestic Product (GDP) deflator from the National Income Accounts.

However, as Freeman (2001) points out, many poor families, for whom government transfers are important, rely more on labour income than on any other resources. Consequently, as real wages rise, more workers might be able to earn sufficient income to escape poverty. To account for this, we include the average real hourly earnings from the US Bureau of Labor Statistics expressed in constant 2000 dollars. Given that these data are available from 1964 onwards, the estimation period is 1964 to 2004.
Moreover, several authors suggest that there should be a variable that controls for the structure of American families given the much higher poverty rate among female-headed families than among the total population (e.g. Enders and Hoover, 2003; Hoover et al., 2004). We therefore include the number of female-headed families from the March Current Population Surveys of the US Census Bureau in our poverty function.

Finally, given that the US poverty rate tends to rise during business cycle downturns and to decline during business cycle expansions, many authors emphasize the need to control for business cycle effects (e.g. Blank and Blinder, 1986; Hoover et al., 2004). To account for this, we include the log-linear detrended ${ }^{1}$ GDP (in constant 2000 prices) as a proxy for the business cycle. The GDP data used to calculate this proxy variable are from the US Department of Commerce.

Thus, the long-run poverty function we estimate is of the form

$$
\begin{aligned}
\ln P_{t}= & c+\alpha_{1} \ln T_{t}+\alpha_{2} \ln E_{t}+\alpha_{3} \ln F_{t} \\
& +\alpha_{4} C_{t}+\xi_{t} \quad t=1, \ldots, T \quad T=41
\end{aligned}
$$

where $\ln P_{t}$ is the logarithm of the poverty rate, $\ln T_{t}$ stands for the logarithm of real government transfers, $\ln W_{t}$ is the logarithm of the real wage, $\ln F_{t}$ represents the logarithm of the number of female family heads, $C_{t}$ denotes the business cycle and $\xi_{t}$ is the usual error term.

\section{Empirical Analysis}

\section{Cointegration test}

Standard unit root tests, as well as Perron structural change tests, suggest that $\ln P_{t}, \ln T_{t}, \ln W_{t}$ and $\ln F_{t}$ are integrated of order one (results not reported here to save space). Consequently, the first step in our analysis is an investigation of the cointegration properties of these time series. Note that the business cycle variable is stationary $[I(0)]$, thus already representing a cointegrating relationship. Therefore, $C_{t}$ is excluded from the cointegration analysis of $\ln P_{t}, \ln T_{t}, \ln W_{t}$ and $\ln F_{t}$.

To test for cointegration between these four variables, we make use of the Johansen (1995) procedure. The Johansen procedure is based on reformulating an $n$-dimensional and $k$ th-order vector $\left(y_{t}\right)$ to a vector error correction model:

\footnotetext{
${ }^{1}$ Detrending using the Hodrick-Prescott filter gives the same results qualitatively.
} 


$$
\Delta y_{t}=\sum_{i=1}^{k-1} \Gamma_{i} \Delta y_{t-i}+\Pi y_{t-1}+\psi D_{t}+\varepsilon_{t},
$$

where $y_{t}=\left[\ln P_{t}, \ln T_{t}, \ln W_{t}, \ln F_{t}\right]^{\prime}$ is a $n \times 1$ vector of the first-order integrated [I(1)] variables, $\Gamma_{i}$ is an $n \times r$ matrix of short-run coefficients, $\Pi$ is a $n \times r$ matrix of long-run parameters and $\psi$ represents an $n \times r$ matrix of coefficients on $D_{t}$, which is a vector of deterministic terms, such as a constant term and a linear time trend. If the data cointegrate, $\Pi$ must be of reduced rank, $r<n$, with $r$ as the number of distinct cointegrating vectors, such that $\Pi=\alpha \beta$, where the matrices $\alpha$ and $\beta$ contain the adjustment parameters and the cointegrating vectors, respectively.

As the determination of cointegration rank is essentially a model specification problem, we use the Schwarz model selection criterion $(S C)$ to determine the number of cointegrating vectors. The Schwarz criterion has been shown to perform as well as, and sometimes better than, the usual trace test and is computed according to the following equation (e.g. Wang and Bessler, 2005):

$$
S C=\ln (\operatorname{det}(\hat{\Sigma}))+J \ln (T) / T,
$$

where $\hat{\Sigma}$ is the maximum likelihood estimator of the variance-covariance $\Sigma$ of the innovation $\left(\varepsilon_{\mathrm{t}}^{\prime}\right.$ 's) with given lag order $k$ and cointegration rank $r$ and $J$ is the number of free parameters in the model, which increases with $k$ and $r$. Because all standard lag selection criteria unanimously select a two-lag model, we calculate $S C$ values for $r=0,1,2$ and 3, conditional on $k-1=2$. Table 1 lists the results. Given that the Schwarz criterion has a minimum at $r=1$, we conclude that the variables are cointegrated with one cointegrating vector.

\section{Parameter estimation}

Having found that the relation $\ln P_{t}-\alpha_{1} \ln T_{t}-\alpha_{2}$ $\ln E_{t}-\alpha_{3} \ln F_{t}$ is stationary, we proceed under the assumption that there is a long-run relationship between $\ln P_{t}, \ln T_{t}, \ln W_{t}$ and $\ln F_{t}$. Because the business cycle is also stationary and because $C_{t}$ is expected to be an important explanatory variable in the fully specified poverty function, the next step is to

Table 1. Determination of the cointegration rank

\begin{tabular}{lllll}
\hline & $r=0$ & $r=1$ & $r=2$ & $r=3$ \\
\hline$S C$ & -15.997 & -16.285 & -16.098 & -15.751 \\
\hline
\end{tabular}

The model includes an unrestricted constant. include $C_{t}$ in the long-run relationship. To this end, we apply the Dynamic Ordinary-Least Square (DOLS) estimation procedure of Stock and Watson (1993). This procedure is robust to the presence of potentially endogenous regressors and allows us to obtain asymptotically efficient estimates of cointegrated models with $I(1)$ and $I(0)$ variables. The DOLS procedure involves regressing $\ln P_{t}$ on a constant, $\ln T_{t}, \ln W_{t}, \ln F_{t}, C_{t}$ and on the leads, lags and contemporaneous values of the first differences of $\ln T_{t}$, $\ln W_{t}$ and $\ln F_{t}$. The result of the DOLS regression with one lead and one lag is ( $t$-statistics in parentheses beneath the estimated coefficients)

$$
\begin{aligned}
& \ln P_{t}=-1.389-0.343 \ln T_{t}-1.564 \ln W_{t} \\
&(-1.39) \quad(-6.90) \quad(-9.16) \\
&+0.740 \ln F_{t}-1.885 C_{t} \\
& \quad(5.28) \quad(-9.18) \\
&+\sum_{i=-1}^{i=+1} \theta_{i} \Delta \ln \left(T_{t+i}\right)+\sum_{i=-1}^{i=+1} \phi_{i} \Delta \ln \left(W_{t+i}\right) \\
&+\sum_{i=-1}^{i=+1} \varphi_{i} \Delta \ln \left(F_{t+i}\right) \\
& \bar{R}^{2}=0.96 \quad \operatorname{JB}=0.71(0.70) \quad \operatorname{RESET}=2.69(0.11) \\
& \operatorname{LM}(1)=0.09(0.76) \quad \operatorname{LM}(3)=0.44(0.73) \\
& \operatorname{LM}(5)=0.25(0.94) \quad \operatorname{ARCH}(1)=0.04(0.83) \\
& \operatorname{ARCH}(2)=0.16(0.85) \quad \operatorname{ARCH}(4)=0.20(0.94)
\end{aligned}
$$

where the numbers in parentheses behind the diagnostic test statistics are the corresponding $p$-values. $\mathrm{JB}$ is the Jarque-Bera test for normality, RESET is the usual test for general nonlinearity and misspecification, $\operatorname{LM}(k)-k=1,3$ and 5 - are Lagrange Multiplier (LM) tests for autocorrelation based on 1,3 and 5 lags, respectively, and $\operatorname{ARCH}(k)$ is an LM test for autoregressive conditional heteroscedasticity of order $k, k=1,2$ and 4 . As all $p$-values exceed the conventional significance levels, we conclude that neither obvious nonlinearity nor misspecification is present and that the residuals show no signs of non-normality, autocorrelation or autoregressive heteroscedasticity. Thus, valid statistical inferences can be drawn from the estimated coefficients.

As expected, the effect of the business cycle on poverty is substantial. The coefficient on $C_{t}$ implies that $1 \%$ upswing in the business cycle leads to $1.885 \%$ decrease in the poverty rate, whereas business cycle troughs increase poverty to the same extent. Also consistent with our expectations, the poverty rate is 
increased by the number of female family heads and reduced by higher wages. The estimated relationship suggests that $1 \%$ increase in female family heads is associated with a $0.740 \%$ increase in poverty, whereas $1 \%$ increase in real wages is associated with $1.564 \%$ decrease in poverty. Turning to the coefficient on $\ln T_{t}$, we see that the relationship between government transfers and poverty is statistically significant negative. More precisely, the coefficient on $\ln T_{t}$ implies that the poverty rate decreases in the long run by $0.343 \%$ because of a $1 \%$ increase in government transfers. Thus, in contrast to most previous studies, we find that government transfers play an important poverty-reducing role.

\section{Robustness}

In the final step, we examine whether the results of Sections 'Cointegration test' and 'Parameter estimation' are robust to alternative estimation techniques. To this end, we use a conditional error-correction model, regressing $\Delta \ln P_{t}$, on $\ln P_{t-1}, \ln T_{t-1}$, $\ln W_{t-1}$ and $\ln F_{t-1}$, the first differences of $\ln T_{t}$, $\ln W_{t}$ and $\ln F_{t}$ up to lag order two, $C_{t}$ up to lag order two, the lagged differences of $\ln P_{t}$, also up to lag order two, and an intercept term. Note that $C_{t}$ does not appear in first differences because the business cycle is already stationary. After applying the generalto-specific model reduction procedure, we obtain the following equation ( $t$-statistics in parentheses beneath the estimated coefficients):

$\Delta \ln P_{t}=-1.200-0.522 \ln P_{t-1}-0.122 \ln T_{t-1}$

$$
\begin{aligned}
& (-1.42) \quad(-7.14) \quad(-2.53) \\
& -0.488 \ln W_{t-1}+0.289 \ln F_{t-1}-1.082 C_{t} \\
& \quad(-2.76) \quad(2.27) \quad(-8.21) \\
& +0.673 \Delta \ln F_{t}-0.751 \Delta \ln W_{t} \\
& \quad(3.07) \quad(-2.70)
\end{aligned}
$$

$$
\begin{aligned}
& \bar{R}^{2}=0.85 \quad \mathrm{JB}=0.66(0.72) \quad \mathrm{RESET}=1.00(0.32) \\
& \mathrm{LM}(1)=0.54(0.47) \quad \operatorname{LM}(3)=0.70(0.56) \\
& \mathrm{LM}(5)=1.43(0.25) \quad \operatorname{ARCH}(1)=2.08(0.16) \\
& \operatorname{ARCH}(2)=1.70(0.20) \quad \operatorname{ARCH}(4)=1.36(0.27)
\end{aligned}
$$

As a significant negative coefficient of the lagged dependent level variable indicates cointegration, the $t$-statistic of the coefficient on $\ln P_{t-1}$ can be used to test for cointegration. The corresponding finitesample critical values can be calculated from the response surfaces in Ericsson and MacKinnon (2002). Because the estimated $t$-statistic $(-7.14)$ exceeds, in absolute value, the finite-sample critical value of -4.62 at the $1 \%$ level, the null of no cointegration is clearly rejected.

Observe, moreover, that the short-run dynamics of $\ln T_{t}$ are not significantly different from zero and therefore do not appear in the equation. This implies that government transfers have no short-term impact on the poverty rate, suggesting that the (positive) work disincentive effects compensate the (negative) income effects of government transfers on the poverty rate in the short run.

Normalizing on the coefficient of $\ln P_{t-1}$ in Equation 5 finally yields the following long-run relationship:

$$
\begin{aligned}
\ln P_{t}= & -0.233 \ln T_{t}-0.935 \ln W_{t} \\
& +0.554 \ln F_{t}
\end{aligned}
$$

Adding the (normalized) impact of the business cycle gives the complete poverty function:

$$
\begin{aligned}
\ln P_{t}= & -0.233 \ln T_{t}-0.935 \ln W_{t} \\
& +0.554 \ln F_{t}-2.073 C_{t}
\end{aligned}
$$

which is close to the result of the DOLS procedure. From this, it follows that the estimates are fairly robust to different estimation techniques.

\section{Conclusion}

This article has examined the long-run impact of government transfers on US poverty by applying cointegration techniques to aggregate time-series data over the period 1964 to 2004. In contrast to most previous studies, we found that government transfers play an important poverty-reducing role. Specifically, our results suggest that, although government transfers have no statistically significant short-term effects on the poverty rate, they significantly reduce poverty in the long run. In addition, we found that (i) an increase in real wages is associated with a decrease in poverty; (ii) an increase in single-mother families is associated with an increase in the US poverty rate and (iii) poverty in the United States is heavily influenced by the business cycle. Summing up, our results demonstrate how recent advances in time-series econometrics can be used to shed more light on the determinants of poverty. 


\section{References}

Balke, N. S. and Slottje, D. J. (1993) Poverty and change in the macroeconomy: a dynamic macroeconomic model, The Review of Economics and Statistics, 75, $117-22$.

Blank, M. and Blinder, A. S. (1986) Macroeconomics, income distribution, and poverty, in Fighting Poverty (Eds.) S. Danziger and D. Weinberg, Harvard University Press, Cambridge, MA.

Enders, W. and Hoover, G. A. (2003) The effect of robust growth on poverty: a nonlinear analysis, Applied Economics, 35, 1063-71.

Ericsson, N. R. and MacKinnon, J. G. (2002) Distributions of error correction tests for cointegration, The Econometrics Journal, 5, 285-318.

Formby, J. P. and Kim, H. (2001) Economic growth and poverty in the United States, Journal of Income Distribution, 10, 6-22.

Freeman, R. B. (2001) The rising tide lifts. NBER Working Paper No. 8155, National Bureau of Economic Research, Cambridge.

Gottschalk, P. and Danziger, S. (1984) Macroeconomic conditions, income transfers, and the trend in poverty, in The Social Contract Revisited (Ed.) D. L. Bawden, Urban Institute Press, Washington, DC.

Gundersen, C. and Ziliak, J. P. (2004) Poverty and macroeconomic performance across space, race, and family structure, Demography, 41, 61-86.

Gwartney, J. and McCaleb, T. S. (1985) Have antipoverty programs increased poverty?, Cato Journal, 5, 1-16.
Haveman, R. and Schwabisch, J. (2000) Has macroeconomic performance regained its antipoverty bite?, Contemporary Economic Policy, 18, 415-27.

Hoover, G. A., Formby, J. P. and Kim, H. (2004) Poverty, non-white poverty, and the Sen-Index, Review of Income and Wealth, 50, 543-59.

Hoynes, H., Page, M. and Stevens, A. (2005) Poverty in America: trends and explanations. NBER Working Paper No. 11681, National Bureau of Economic Research, Cambridge.

Johansen, S. (1995) Likelihood-Based Inference in Cointegrated Vector Autoregessive Models, Oxford University Press, New York.

Nieswiadomy, M., Hayes, K. and Slottje, D. J. (1991) An analysis of the relationship between various redistributive programs and poverty, Public Choice, 68, 175-84.

Osberg, L. (2000) Poverty in Canada and the United States: measurement, trends, and implications, Canadian Journal of Economics, 33, 847-77.

Peterson, P. E. and Rom, M. (1989) American federalism, welfare policy, and residual choices, The American Political Science Review, 83, 711-28.

Stock, J. H. and Watson, M. W. (1993) Simple estimator of cointegrating vectors in higher order integrated systems, Econometrica, 61, 783-820.

Vedder, R. K. and Gallaway, L. E. (2001) Does the Minimum Wage Reduce Poverty?, Employment Institute, Ohio University, Athens.

Wang, Z. and Bessler, D. A. (2005) A Monte Carlo study on the selection of cointegrating rank using information criteria, Econometric Theory, 21, 593-620. 